\title{
Correction to: Pathophysiology of Gastroparesis Syndromes Includes Anatomic and Physiologic Abnormalities
}

\author{
Thomas L. Abell ${ }^{1}$ - Archana Kedar $^{1} \cdot$ Abigail Stocker $^{1} \cdot$ Karen Beatty $^{1} \cdot$ Lindsay McElmurray $^{1} \cdot$ Michael Hughes $^{2}$. \\ Hani Rashed ${ }^{1}$. William Kennedy ${ }^{3} \cdot$ Gwen Wendelschafer-Crabb $^{3} \cdot$ Xiu Yang $^{4} \cdot$ Mostafa Fraig $^{4} \cdot$ Leila Gobejishvili $^{1}$. \\ Endashaw Omer $^{1} \cdot$ Ed Miller $^{1} \cdot$ Michael Griswold ${ }^{5} \cdot$ Christina Pinkston $^{6}$
}

Published online: 8 June 2020

(c) Springer Science+Business Media, LLC, part of Springer Nature 2020

\section{Correction to: Digestive Diseases and Sciences https://doi.org/10.1007/s10620-020-06259-6}

The original version of the article requires some updates to the affiliation of authors in the author group.

Affiliation of authors Lindsay McElmurray, Dr. Michael Hughes, Dr. Hani Rashed, Dr. William Kennedy, Dr. Gwen Wendelschafer-Crabb, Dr. Xiu Yang, Dr. Mostafa Fraig and Christina Pinkston are updated through this erratum.

Publisher's Note Springer Nature remains neutral with regard to jurisdictional claims in published maps and institutional affiliations.

The original article can be found online at https://doi.org/10.1007/ s10620-020-06259-6.

Thomas L. Abell

thomas.abell@1ouisville.edu

1 Division of Gastroenterology, Hepatology and Nutrition,

University of Louisville, 550 S. Jackson, ACB A3L15,

Louisville, KY 40202, USA

2 Department of Surgery, University of Louisville, Louisville, KY, USA

3 Department of Neurology, University of Minnesota, Minneapolis, MN, USA

4 Department of Pathology, University of Louisville, Louisville, KY, USA

5 Department of Biostatistics, University of Mississippi, Jackson, MS, USA

6 Department of Bioinformatics and Biostatistics, School of Public Health and Information Sciences, University of Louisville, Louisville, KY, USA 